\title{
SUBALTERNIDADE, REPRESENTAÇÃO E MERCADO: $O$ QUE ESCREVEM AS MOÇAMBICANAS?
}

\author{
Anselmo Peres Alós \\ Universidade Federal de Santa Maria
}

\begin{abstract}
Resumo: Lília Momplé e Paulina Chiziane, através de suas narrativas, resgatam os dilemas da constituição da nacionalidade através das experiências de personagens relegados à margem. Apesar de sua importância, o nome destas escritoras raramente é mencionado nos estudos brasileiros sobre as literaturas africanas de língua portuguesa. Por que esta ausência? Compreender esta ausência é compreender muito do que está atravancado no meio do longo caminho que separa o público leitor brasileiro das literaturas africanas de língua portuguesa, e em especial, da literatura moçambicana: a circulação de livros e a lógica do mercado editorial em tempos marcados pelos resíduos das políticas culturais colonialistas.
\end{abstract}

Palavras-chave: Lília Momplé. Paulina Chiziane. Autoria feminina. Usos da literatura. Narrativa moçambicana.

\section{Preâmbulo: primeiros acordes}

\begin{abstract}
What is important in the work is what it does not say. This is not the same as the careless notation "what it refuses to say", although that would in itself be interesting: a method might be built on it, with the task of measuring silences, whether acknowledged or unacknowledged. But rather than this, what the work cannot say is important, because there the elaboration of the utterance is acted out, in a sort of journey to silence ${ }^{1}$
\end{abstract}

(MACHERAY, 1978, p. 87)

\section{(c) (1)} BY Esta obra está licenciada sob uma Creative Commons - Atribuição 4.0

\footnotetext{
* Doutor em Literatura Comparada pela Universidade Federal do Rio Grande do Sul (UFRGS). Professor Adjunto III na Universidade Federal de Santa Maria (UFSM). Docente permanente do Programa de PósGraduação em Letras da mesma instituição. Coordenador do Projeto de Pesquisa Ressonâncias e dissonâncias do romance lusófono contemporâneo: o imaginário pós-colonial e a desconstrução da identidade nacional. Líder do Grupo de Pesquisa Trânsitos teóricos e deslocamentos epistêmicos: feminismo(s), estudos de gênero e teoria queer, cadastrado junto ao Diretório Nacional dos Grupos de Pesquisa do CNPq. Autor de A letra, o corpo e o desejo: masculinidades subversivas no romance latino-americano contemporâneo (Florianópolis: Mulheres, 2013). E-mail: anselmoperesalos@gmail.com.

1 “O importante em uma obra literária é aquilo que ela não diz. Isso não significa o mesmo que a descuidada afirmação de que é "aquilo que a obra se recusa a dizer", embora tal afirmação também seja interessante: uma metodologia pode ser construída a partir disso, com o objetivo de medir os silêncios, sejam esses reconhecidos ou não. Porém, mais do que isso, o que a obra literária não pode dizer é importante, pois aí a elaboração do enunciado é executada em uma espécie de jornada ao silêncio" (tradução nossa, grifos no original).
} 
Estar-se-ia vivendo um período de globalização do imaginário, correlativo à globalização do capital econômico e das relações internacionais? Ou será que a literatura, na contramão da globalização econômica do planeta, estaria a funcionar como um processo discursivo que, a contrapelo da homogeneização, insiste no caráter irredutível da diferença como capital cultural fundamental na economia das relações humanas? $O$ escritor moçambicano Mia Couto, talvez um dos mais representativos romancistas da África lusófona contemporânea, ao lado de outros como Germano Almeida (Cabo Verde) e Pepetela (Angola), é reconhecido pela crítica em função do talento inventivo que expressa em seus escritos, que vai desde o nível lexical, com a criação de neologismos inspirados nos usos populares do português, até a fabulação de universos que beiram o realismo mágico, como no romance $O$ último voo do flamingo (2004).

Cabe salientar, entretanto, que não é apenas o apelo poético dos escritos de Mia Couto que chama a atenção de seus leitores e críticos mundo afora. O poder de subversão cifrada através das imagens poéticas narradas nas histórias de Mia Couto extrapola os domínios da norma culta da língua portuguesa. Por detrás das inúmeras metáforas e neologismos, há um profundo senso de intervenção política a marcar a obra do escritor moçambicano, tal como ele mesmo afirma: "estou a falar e escrever em um momento em que a nossa democracia [moçambicana], que é uma conquista de todos nós, está a ser posta em causa todos os dias, e está ser posta em causa gravemente por ameaças de violência, por comportamentos profundamente antidemocráticos" (COUTO apud ANÔNIMO, 2009, p. 3).

Este senso de compromisso político com os processos históricos de consolidação da sociedade moçambicana torna-se ainda mais saliente quando se passa a trabalhar com a literatura de autoria feminina. Nesse contexto em que a democracia moçambicana se vê posta em causa cotidianamente, cabe a retomada da célebre discussão articulada por Gayatri Chakravorty Spivak em Pode o subalterno falar? Em outras palavras, o que interessa aqui é ler, no contexto identificado por Mia Couto, um contexto de "ameaças de violência, [e marcado] por comportamentos profundamente antidemocráticos" (idem, ibidem), as vozes duplamente silenciadas das mulheres negras moçambicanas no cenário da produção literária pós-independência. De acordo com Sandra Almeida:

$\mathrm{Na}$ análise de Spivak, há uma relação intrínseca entre o "falar por" [Vertretung] e o "re-presentar" [Darstellung], pois, em ambos os casos, a representação é um ato de fala em que há a pressuposição de um falante e de um ouvinte. A autora argumenta ainda que o processo de fala se caracteriza por uma posição discursiva, uma transação entre falante e ouvinte e, nesse sentido, conclui afirmando que esse espaço dialógico de interação não se concretiza jamais, pois o sujeito subalterno que, 
desinvestido de qualquer forma de agenciamento, de fato, não pode falar (ALMEIDA, 2010, p. 13).

\section{Uma balada para Paulina}

Celebrada pelos círculos literários como a primeira mulher moçambicana a publicar um romance, Paulina Chiziane vem ganhando amplitude, ao lado de nomes como o de Lília Momplé, como uma das romancistas de maior destaque do final do século XX e início do século XXI, com um obra de grande repercussão não apenas em Moçambique, mas em toda a África lusófona. Entre seus romances, cabe destacar Balada de amor ao vento (1990), Ventos do apocalipse (1993), O sétimo juramento (2000), Niketche: uma história de poligamia (2002) e O alegre canto da perdiz (2008).

Balada de amor ao vento, publicado pela primeira vez em 1990 pela Associação dos

Escritores Moçambicanos (AEMO), e reeditado em 2007 pela Editora Caminho de Lisboa (volume 17 da coleção Outras Margens), traz à baila o conflituoso embate de certos valores tribais autóctones com as diretrizes sociais ocidentalizadas. Tal embate termina por redimensionar a configuração da organização familiar moçambicana, em especial no que toca aos papéis sociais exercidos pelas mulheres, tanto na esfera pública quanto na privada.

De acordo com a autora, "a terra é a mãe da natureza e tudo suporta para parir a vida. Como a mulher. Os golpes da vida a mulher suporta no silêncio da terra. Na amargura suave segrega um líquido triste e viscoso como o melão" (CHIZIANE, 2007, p. 12). No vórtex dessa turbulência, quem mais sofre são as mulheres, impedidas de constituir identidades viáveis, e mesmo de participar efetivamente da vida pública como cidadãs plenas. Papel decisivo no cerceamento da liberdade das mulheres é exercido pelas superstições oriundas das religiões bantu, como afirma a própria autora em texto posterior à publicação do romance:

\footnotetext{
Nas religiões bantu, todos os meios que produzem subsistência, riqueza e conforto como a água, a terra e o gado são deificados, sacralizados. A mulher, mãe da vida e força da produção da riqueza, é amaldiçoada. Quando uma grande desgraça recai na comunidade sob a forma de seca, epidemias, guerra, as mulheres são severamente punidas e consideradas as maiores infractoras dos princípios religiosos da tribo pelas seguintes razões: são os ventres delas que geram feiticeiros, as prostitutas, os assassinos e os violadores de normas. Porque é o sangue podre das suas menstruações, dos seus abortos, dos seus natimortos que infertiliza a terra, polui os rios, afasta as nuvens e causa epidemias, atrai inimigos e todas as catástrofes (CHIZIANE, 1992, p. 12).
}

No confronto entre os valores da modernidade ocidental e os preceitos autóctones que, ainda hoje, pautam fortemente a organização social moçambicana, a escrita romanesca de autoria feminina ganha uma importância fundamental no processo de constituição de 
alternativas identitárias viáveis para as mulheres. Entende-se aqui a categoria identidade nos mesmos termos apresentados por Rita Terezinha Schmidt:

Identidades são concebidas aqui como movimentos contínuos/descontínuos das
relações que sujeitos, comunidades, nações estabelecem imaginariamente com o
outro, o que garante sua auto-constituição e sua inserção dentro de certas condições
sócio-históricas e discursivas que são, elas próprias, sustentáculos daquelas relações.
Nesse sentido, as identidades resultam de tecnologias de produção de subjetividades,
cujas representações simbólicas são, por excelência, o lugar da ideologia
(SCHMIDT, 2000, p. 103).

A história de amor entre Sarnau e Mwando, permeada de encontros e desencontros, é o eixo a partir do qual se aciona a memória da personagem central de Balada de amor ao vento, que realiza uma retomada de sua conturbada trajetória a levar-lhe da riqueza e da realeza à miséria. $\mathrm{O}$ casamento poligâmico ainda na adolescência, a traição ao marido com um homem amado desde a infância, a fuga da aldeia e a sobrevivência em meio à miserável Mafalala (bairro pobre nos arredores de Maputo) encaixa-se em uma torrente de eventos nos quais a constante mais forte é o permanente questionamento das convenções sociais relativas aos papéis femininos no contexto familiar moçambicano. A economia narrativa arregimentada pela autora, que alterna uma voz narrativa extradiegética com focalização externa e uma voz narrativa intradiegética com focalização interna, permite sublinhar os sentimentos de Sarnau frente ao modus operandi hegemônico.

Vivendo em Mambone ${ }^{2}$, Sarnau é abandonada grávida por Mwando, um exseminarista, após ter vivido com ele uma história de amor extraconjugal repleta de esperanças. Mwando abandona Sarnau para casar com Sumbi, moça cristã escolhida para ser sua esposa, em um casamento monogâmico, de acordo com as regas pregadas pela igreja católica. Desesperada, ao receber a notícia de Mwando, a jovem termina perdendo o filho em uma tentativa de suicídio. Sua vida muda quando é eleita para ser a primeira esposa de Nguila, herdeiro da tribo dos Zucula. Tal como manda a tradição, os Zucula têm de pagar o lobolo à família da noiva, para que essa dê sua permissão para a realização do casamento.

Cabe aqui uma breve explanação acerca do lobolo, uma vez que, ainda que antropologicamente "aparentado" com a prática do pagamento do dote, esse funciona de acordo com uma lógica cultura bastante peculiar, relativamente comum entre os povos agrários subsaarianos. Na região moçambicana ao sul do Save, os casamentos costumavam (e, nas regiões rurais, ainda costumam) ser tratados como uma questão privada, mas resolvida coletivamente entre dois grupos, e concluída sem intervenção das autoridades, fossem elas

\footnotetext{
${ }^{2}$ Localizada na província de Inhambane, no sul de Moçambique, Mambone carrega a reputação de ser a terra dos mais poderosos nhamussoros (feiticeiros tradicionais) de todo o país.
} 
políticas ou religiosas. O objetivo primeiro do casamento, tal como celebrado nestas sociedades tribais e agrárias, era a produção de novos indivíduos para o clã (os quais, em um futuro próximo, deveriam assumir o papel de provedores, assegurando a sobrevivência do mesmo como corpo coletivo organizado). As negociações entre os dois grupos distintos (representados pelo noivo e pela noiva) eram conduzidas por membros de destaque das famílias interessadas, sendo o consentimento dos noivos para o casamento um pressuposto.

A permissão para a união era vista, pelos dois grupos, como uma espécie de "troca de serviços" entre clãs distintos: um deles cedia ao outro as capacidades reprodutivas de um dos seus membros (o ventre feminino) e, a título de compensação por esta "perda", o clã reclamava determinados bens (também chamados, em seu conjunto, de lobolo), os quais, via de regra, acabavam sendo destinados à aquisição de uma noiva para um dos irmãos da recémcasada, aquisição esta realizada dentro da mesma lógica e dos mesmos preceitos aqui descritos ${ }^{3}$.

De maneira sintética, pode-se dizer que as funções do lobolo nestas aldeias eram múltiplas. Primeiramente, esta prática representava uma espécie de compensação (no sentido lato), e não um "dote" ou um "preço de compra" pela noiva (a ser pago pelo noivo), como tem sido erroneamente considerado (mesmo em Moçambique). Em seguida, a prática do lobolo, vista como uma instituição cultural autóctone, autorizava a transferência da capacidade reprodutora da mulher para o grupo familiar do marido em função do "pagamento" do lobolo. Em terceiro lugar, o lobolo atribui legitimidade, legalidade (nas sociedades tradicionais) e estabilidade $^{3}$ à união matrimonial. Em quarto lugar, ele resposabilizava tanto o marido quanto a família deste pela manutenção e pelo bem-estar da mulher lobolada, bem como dos filhos desta, frente à comunidade. Em quinto lugar, funcionava como ritual simbólico de legitimação dos filhos gerados, os quais eram considerados então membros pertencentes à família do noivo, isto é, à família que havia pago o lobolo. Finalmente, a paga do lobolo constituía um meio de aquisição de outra unidade reprodutora para o grupo enfraquecido, isto é, para a aquisição de uma noiva para um dos homens da família da mulher lobolada, frequentemente para o irmão mais velho da noiva ${ }^{4}$.

\footnotetext{
${ }^{3}$ António RITA-FERREIRA, 1967-68, p. 291.

${ }^{4}$ Tive a oportunidade de lecionar, entre 2009 e 2011, em diferentes instituições de Ensino Superior em Maputo, capital de Moçambique, tais como o Instituto Superior de Ciências e Tecnologia de Moçambique (ISCTEM), o Instituto Superior de Comunicação e Imagem de Moçambique (ISCIM), o Centro Cultural Brasil-Moçambique (CCBM) e a Universidade Islâmica Mussá Bin Bique. Conversando informalmente com minhas alunas (oriundas da classe média urbana de Maputo), descobri que a grande maioria delas considerava o lobolo conditio sine qua non para que se casassem, pois atribuíam a esta prática a capacidade de assegurar a estabilidade e a perenidade da união com seus maridos. Curiosamente, o valor atribuído ao lobolo como ritual que assegurava as bênçãos à
} 
Compreender a complexa dinâmica do lobolo é de fundamental importância para que se compreenda o desfecho de Balada de amor ao vento ${ }^{5}$. O casamento com Nguila eleva Sarnau à condição de futura rainha dos Zucula, posto que alcança por ocasião da morte do pai e da mãe de seu marido, que vem a ocupar o trono. Contudo, mesmo com sua privilegiada condição social, a qual lhe é garantida pela sua posição como esposa do rei Nguila, Sarnau sofre imensamente em função da violência e das imposições às quais se submete em função em função da poligamia. Nguila possui outras esposas (seis ao total), espanca Sarnau constantemente e lhe exige um filho. Como primeira esposa de Nguila, Sarnau é a única com legitimidade para gerar um descendente para o trono. Ela, contudo, dá à luz duas meninas gêmeas. Paralelamente, Mwando é traído e abandonado por Sumbi.

A educação cristã não levou Mwando apenas a rechaçar a poligamia, mas também a defender a relativização das funções sociais atribuídas aos homens e mulheres em sua tribo. Sumbi tirava proveito disso, obrigando-o a assumir as tarefas que os outros homens, membros do clã, consideravam indignas e reservadas às mulheres, tais como cozinhar, lavar e cuidar da casa. Depois de abandonado por Sumbi, Mwando regressa a Mambone, reencontra Sarnau e ambos reiniciam seus encontros sexuais.

Sexualmente rejeitada pelo marido, que tem franca preferência pela quinta esposa, Phati, Sarnau entrega-se a Mwando, sem saber, entretanto, como fugir do seu casamento com Nguila. Grávida de Mwando, Sarnau se vê obrigada a forçar uma relação sexual com Nguila que sequer a procurava - para ocultar a evidência da traição. Nasce assim o novo herdeiro do trono dos Zucula. Descoberta em sua traição por Phati, Sarnau se vê obrigada a fugir da ira de seu marido, deixando os filhos com Nguila, temerosa de que a origem bastarda de seu filho seja descoberta. Em pequenos barcos, chegam a Vilanculos, uma pequena aldeia de pescadores situada na província de Inhambane, onde Mwando torna-se pescador e Sarnau passa a ter uma vida tranquila. É neste ponto que um antigo companheiro de Mwando, sob o mando de Nguila, busca Sarnau e seu amante para entregá-los ao rei. Por amizade, previne

união entre um homem e uma mulher também se fazia presente entre as alunas muçulmanas e católicas, fossem elas negras moçambicanas, fossem elas descendentes de imigrantes indianos e paquistaneses.

${ }^{5}$ Antes de se realizar julgamentos de valor ocidentalistas acerca da prática do lobolo, cabe relembrar as palavras de Gayatri Chacravorty Spivak acerca da mulher subalterna, quando essa é tomada como objeto de construção de conhecimento por parte de um intelectual ocidental: "ao buscar aprender a falar ao (em vez de ouvir ou falar em nome do) sujeito historicamente emudecido da mulher subalterna, o intelectual pós-colonial sistematicamente 'desaprende' o privilégio feminino. Essa desaprendizagem sistemática envolve aprender a criticar o discurso pós-colonial com as melhores ferramentas que ele proporcionar e não apenas substituindo a figura perdida do(a) subalterno(a)" (SPIVAK, 2010, p. 88). Para considerações mais aprofundadas sobre a prática do lobolo em Moçambique, conferir António RITA-FERREIRA (1967-68), Felizardo CIPIRE (1996), Henri JUNOD (1996) e Paulo GRANJO (2005).

Anu. Lit., Florianópolis, v. 20, n. 2, p. 165-180, 2015. ISSNe 2175-7917 
Mwando que, acovardado, abando Sarnau pela segunda vez, que se encontra esperando um filho seu.

Novamente sozinha, e com um filho no ventre prestes a nascer, Sarnau erra de vila em vila até chegar à Mafalala, bairro pobre de Lourenço Marques (nome colonial da capital moçambicana à época da história, hoje chamada Maputo), onde passa a vender o corpo para sobreviver. Acometida por uma grave doença venérea, Sarnau tem mais um filho, fruto de um affair com um homem casado que não assume a paternidade, passando finalmente a viver como mamana vendedeira, vendendo tomates e alfaces nos mercado livres da Mafalala. Após abandonar Sarnau pela segunda vez, Mwando envolve-se com a mulher de um português e, descoberto por este, acaba deportado para Angola, onde trabalha como escravo nas plantações de cana e café. Lançando mão de seus conhecimentos religiosos, atua como sacerdote, ganhando respeito dos outros trabalhadores escravizados e a alcunha de "Padre Moçambique". Quinze anos depois, Mwando é liberto, e emerge então o desejo de retornar à Maputo em busca de Sarnau. Gasta praticamente todas suas economias nesta viagem de regresso e, no caminho para Lourenço Marques, passa por Mambone, onde descobre que Sarnau havia começado a se prostituir na Mafalala.

Chegando finalmente à Lourenço Marques, Mwando surpreende Sarnau e lhe propõe recomeçar sua vida em comum. Sarnau culpa Mwando por todas as misérias que teve de enfrentar. Forçando a entrada na palhota ${ }^{6}$ de Sarnau, Mwando depara-se com os filhos de Sarnau. Atendendo ao apelo dos filhos, que reconhecem Mwando como pai, Sarnau cede e aceita Mwando em sua palhota, mesmo sabendo que muito provavelmente terá de sustentá-lo pelo resto de sua vida. A trajetória de múltiplas explorações superpostas sobre a subjetividade de Sarnau (exploração do corpo e do trabalho, das capacidades reprodutivas, bem como do papel simbólico das mulheres nos imaginários bantu e cristão, sempre a partir de uma lógica colonialista imposta sobre corpos, afetos e psiquês das mulheres) pode ser lida a partir da afirmação de Spivak:

[...] apesar de ambos [homens e mulheres pós-coloniais] serem objetos da historiografia da insurgência, a construção ideológica de gênero mantém a dominação masculina. Se, no contexto da produção colonial, o sujeito subalterno não tem história e não pode falar, o sujeito subalterno feminino está ainda mais profundamente na obscuridade (SPIVAK, 2010, p. 66-67).

Balada de amor ao vento é um romance sintomático do entrelugar da enunciação pós-colonial. Como tal, mostra-se permeado por contradições e ambiguidades. Com relação a

\footnotetext{
${ }^{6}$ Termo utilizado no português moçambicano para designar as pequenas casas das pessoas humildes, geralmente situadas fora do perímetro urbano. A palavra faz alusão à cobertura de palha utilizada nas construções.
} 
estas ambivalências e contradições que se entrelaçam nos nós e fios urdidos pela narradora, cabe retomar uma reflexão de Homi Bhabha com relação à problemática experiência da escrita da nação:

\begin{abstract}
Se, em nossa teoria itinerante, estamos conscientes da metaforicidade dos povos de comunidades imaginadas - migrantes ou metropolitanos - então veremos que o espaço do povo-nação moderno nunca é simplesmente horizontal. Seu movimento metafórico requer um tipo de "duplicidade" de escrita, uma temporalidade de representação que se move entre formações culturais e processos sociais sem uma lógica causal centrada. $\mathrm{E}$ tais movimentos culturais dispersam o tempo homogêneo, visual, da sociedade horizontal. A linguagem secular da interpretação necessita então ir além da presença do olhar crítico horizontal se formos atribuir autoridade narrativa adequada à "energia não-sequencial proveniente da memória histórica vivenciada e da subjetividade". Precisamos de um outro tempo de escrita que seja capaz de inscrever as interseções ambivalentes e quiasmáticas de tempo e lugar que constituem a problemática experiência "moderna" da nação ocidental (BHABHA, 1998, p. 201).
\end{abstract}

A protagonista do romance, Sarnau, se vê dividida entre um pensamento questionador, que busca a emancipação feminina e que está pautado no pensamento moderno ocidental, as práticas culturais autóctones arcaicas, responsáveis pelo delineamento de sua identidade cultural como mulher moçambicana, e o seu amor incomensurável por Mwando, que termina por levá-la a um sem fim de desventuras. Os dilemas contraditórios (que emergem na construção narrativa da personagem Sarnau) não se devem a problemas de composição não resolvidos por Paulina Chiziane, mas sim à própria economia narrativa póscolonial, que se inscreve como condição de possibilidade para a enunciação de Balada de amor ao vento.

\title{
Um canto para Lília
}

Lília Maria Clara Carrière Momplé nasceu em 19 de Março de 1935, na mítica Ilha de Moçambique, localizada ao norte do país, na província de Nampula. Concluiu seus estudos secundários na capital da colônia, na cidade de Lourenço Marques (hoje Maputo). Na universidade, frequentou durante dois anos o curso de Filologia Germânica, deixando-o para formar-se em Serviço Social no Instituto Superior de Serviço Social de Lisboa. Depois de uma temporada na Grã-Bretanha (durante 1964) e de outra no Brasil (de 1968 a 1971), a escritora regressa definitivamente a Moçambique, no ano de 1972.

Apesar de suas colaborações dispersas na imprensa, Lília Momplé destaca-se no cenário da literatura moçambicana por seus três livros: Ninguém matou Suhura (contos, $1988^{7}$ ), Neighbours (romance, 1996) e Os olhos da cobra verde (contos, 1997). Em 2001, foi

\footnotetext{
${ }^{7}$ Cita-se, neste artigo, a edição de 2007.
} 
agraciada com o Prêmio Caine para Escritores da África, com o conto "O baile de Celina" (publicado no volume Ninguém matou Suhura). Além desse prêmio, recebeu também o $1^{\circ}$ Prêmio de Novelística no Concurso Literário do Centenário da Cidade de Maputo, com o conto "Caniço" (também publicado em Ninguém matou Suhura). Lília Momplé tem livros traduzidos para o inglês e o alemão, por editoras de reconhecido prestígio, tal como a Heinman.

Depois de 11 anos sem reedição, vem a lume, em 2008, a segunda edição de seu segundo livro de conto, intitulado Os olhos da cobra verde. Trata-se um livro composto por seis contos, todos eles "baseados em factos verídicos ocorridos em Moçambique" (MOMPLÉ, 2008, p. 94), como a própria autora afirma, ao final da coletânea. Todos eles estão ambientados em Moçambique, em um período situado desde os fins da guerra civil que se seguiu à independência nacional que ocorreu em 1975 (como "O sonho de Alima” ou "Os olhos da cobra verde") até o período imediatamente posterior à assinatura do Acordo Geral de Paz, em Roma, no ano de 1992 (como em “Stress” ou "Um canto para morrer”).

No conto "Stress", são contadas duas histórias paralelas, que se entrecruzam em um momento trágico. De um lado, conta-se a história da amante do major-general, e de como ela consegue sair de Malhangalene (um dos bairros pobres e periféricos de Maputo) e estabelecerse na Polana, o bairro mais caro da capital moçambicana, graças às benesses que lhe são propiciadas pelo amante. De outro, conta-se a história de um professor anônimo que, nas tardes de domingo, toma sua cerveja, tentando afogar as agruras oriundas das preocupações, com os ouvidos colados em seu xirico (um pequeno radinho de pilhas) e às vistas da amante do major-general, que olha entediada para este quadro todas as tardes de domingo.

A indiferença do professor aos olhares provocantes da amante leva-a a depor contra o professor, quando este é condenado, em função do assassinato da própria esposa:

\footnotetext{
Neste dia, a amante do major-general será a única testemunha de acusação. Nem mesmo os familiares da esposa do réu se prestarão a depor contra ele, porque, apesar de campónios analfabetos, carregam em si uma sabedoria antiga que lhes permite distinguir um criminoso de um homem acuado pelo desespero.

A amante do major-general, porém, logo que tiver conhecimento da tragédia, ousando mesmo contrariar o amante, apresentar-se-á como testemunha de acusação, aproveitando-se da privilegiada situação de vizinha do réu. E, nessa hora de vingança, incriminará o mesmo com afirmações temerárias e falsas. E, a certa altura, dirá mesmo, peremptória: "O réu cometeu o crime premeditadamente. Ele não gosta de mulheres, eu acho!" (MOMPLÉ, 2008, p. 12).
}

Em "Os olhos da cobra verde", a narradora fala dos augúrios prenunciados pela aparição de uma cobra verde a sinalizar boas notícias. Entretanto, a leitura dos sinais da tradição é apenas o pretexto para que Vovó Facache relembre os últimos anos de sua vida, 
desde a fuga de sua terra natal até o seu presente, vivendo na Mafalala: "és então tu a Cobra Verde, da terra do meu pai? Vieste aqui parar, talvez como eu, fugida de tanta guerra, não é?, pergunta ela, em voz alta pois tem a estranha sensação de ser entendida pela Cobra" (MOMPLÉ, 2008, p. 23).

Vovó Facache é uma velha senhora negra moçambicana, originária do norte do país, que migrou para o sul em função dos conflitos entre a Frente de Libertação de Moçambique (FRELIMO) e a Resistência Nacional de Moçambique (RENAMO) ao longo da Guerra dos 16 anos, conflito civil que seguiu logo após a independência do país em 1975. A partir do motivo mítico tradicional, a voz narrativa vai articulando as dificuldades, lembranças e tristezas de Vovó Facache com o período histórico no qual se estendeu a Guerra dos 16 anos.

O lirismo com o qual a voz narrativa constrói a imagem da personagem Vovó Facache, colocando uma mulher simples e humilde em um lugar privilegiado ao colaborar para a construção da identidade nacional moçambicana, ecoa simultaneamente os procedimentos utilizados em Sangue negro (2001), volume póstumo de poemas de Noémia de Souza. O bom augúrio dado pela aparição da Cobra Verde, já no fim da vida de Vovó Facache, configura-se como uma importante estratégia narrativa, no sentido de recuperar e valorizar as tradições ancestrais dos moçambicanos autóctones, embora funcione, da mesma maneira que a madeleine de Marcel Proust, como o "gatilho" que aciona a memória da protagonista:

- Que pode acontecer-me de bom, agora que minha vida já quase terminou? Não só pela idade, mas também por esta guerra estúpida que tudo me roubou. De tantos filhos que criei nem sei quais estão ainda vivos ou se morreram todos. Nem eles sabem de mim, aqui perdida, nesta terra que não conhecem. Mas, no entanto, a Cobra Verde...

Tudo isso pensa Vovó Facache a caminho da sua palhota, decrépita como ela, precário refúgio dos seus últimos anos. Construída por ela própria coma africana solidariedade de alguns vizinhos, não passa de um casinhoto de caniço coberto de colmo, mas é nela que Vovó Facache repousa das noites sofridas no esconderijo da praia e é também nela que prepara as refeições frugais com o pouco que consegue arrancar da exígua machamba (MOMPLÉ, 2008, p. 24).

Repisando todos os seus passos, desde sua juventude no norte até a vida pobre e precária na periferia de Maputo, na Mafalala, o conto culmina então com uma mensagem de esperança: pouco tempo depois do encontro com a Cobra Verde, surgem dois delegados distritais, trazendo as notícias do selamento do Acordo Geral de Paz e do fim da Guerra, tal como anunciado pela chegada da Cobra Verde.

Já no conto "O sonho de Alima", a voz narrativa conta a história de Alima Momade, e da sua tardia festa de formatura na quarta classe, já com mais de quarenta anos. Alima, 
mulher de origem humilde, é eleita por Momplé para metonimicamente representar as dificuldades enfrentadas pelas mulheres na machista sociedade moçambicana. Os percalços enfrentados pela protagonista em seu obstinado périplo para aprender a escrever ilustram as dificuldades enfrentadas pelas moçambicanas na sua busca por direitos básicos, tais como o acesso à educação e o tratamento igualitário por parte de seus companheiros. A protagonista do conto, Alima Momade, se vê proibida pelo marido de frequentar as aulas de alfabetização, uma vez que o marido de Alima vê, em uma mulher alfabetizada, uma ameaça ao equilíbrio tradicional do casamento. Para ele, a alfabetização é vista como uma maneira de assimilação da esposa à cultura colonialista, e uma vez assimilada, Alima pode não mais respeitar os costumes tradicionais. Um elemento formal importante aqui é que, enquanto a personagem feminina - Alima Momade - tem nome e sobrenome, o marido é mencionado ao longo de todo o conto apenas como "o marido". Em um gesto estratégico, Lília Momplé não atribui nome ao marido, evidenciando assim, e não sem um tanto de ironia, o apagamento da individualidade das mulheres que, reiteradamente, são reduzidas ao papel de esposas, com a elisão do próprio nome, sendo chamadas por seus companheiros simplesmente de esposa ou mamana.

Mas Alima não desiste do seu sonho de adentrar o mundo letrado: abandona o marido e vai viver sozinha, com todas as dificuldades que esta ação implica para uma mulher em uma comunidade moçambicana de valores tradicionais, apenas para poder concluir seus estudos. Depois de muito sofrer pela ausência da esposa, o marido implora que ela retorne para casa, e permite que Alima continue frequentando a escola noturna. As dificuldade enfrentadas pelas mulheres moçambicanas, por ocasião de sua inserção no universo escolar, também são tematizada em seu livro anterior, Ninguém matou Suhura, particularmente no conto "O baile de Celina", no qual explora a questão do racismo institucionalizado no aparelho ideológico escolar (ALÓS, 2011a; 2011b). Em “Um canto para morrer”, também é retratado o problema das assimetrias das relações de gênero em Moçambique, enfocando agora não a questão do acesso à educação, mas a da submissão das esposas aos maridos em um contexto bastante particular: o dos arrendamentos, da compra e da venda de imóveis em Maputo.

Em "Xirove", Lília Momplé conta a história de Salimo, jovem que acabou juntandose às tropas de guerrilha da RENAMO, lembradas ainda hoje em Moçambique pela crueldade nos tempos de guerra, quando tomavam e saqueavam as pequenas aldeias, estuprando as mulheres, assassinando todos os adultos e sequestrando as crianças para serem treinadas e 
colocadas na linha de frente de batalha. Não foi o caso de Salimo, que abandonou sua família e sua aldeia para fugir ao amor proibido que sentia por Rafa, a prometida de seu irmão e que, posteriormente, terminou por se juntar às tropas da RENAMO. Retornando ao seio de sua família, começam os preparativos para o seu xirove.

O xirove é um rito tradicional dos Macua (o grupo étnico mais numeroso em Moçambique), que tem como finalidade reintegrar à comunidade alguém que cometeu um grave delito ${ }^{8}$. Ao tomar o xirove (uma espécie de beberagem preparada com ervas), o criminoso aceita a culpa pelos seus crimes, comprometendo-se a nunca mais os repetir. Em seguida, já purificado, o indivíduo deve participar do primeiro batuque ou festa realizado pela comunidade, para que a reintegração do indivíduo ao grupo seja consolidada. Este rito, dotado da força simbólica comum a todos os rituais ancestrais, reabilita Salimo a viver na sua aldeia natal.

Entretanto, um outro motivo leva Salimo a abandonar a aldeia pela manhã, logo cedo, após a festa de promoção de sua reintegração à comunidade: Salimo está apaixonado pela esposa de seu irmão e, imaginando-se incapaz de resistir à beleza de Rafa, deixa logo cedo a aldeia, como um andarilho:

Assim, nesta manhã brumosa e quente, acaba de despedir-se da família que se aglomera à porta da palhota e o vê partir pelo carreiro que leva à estrada principal. De repente, relâmpagos em cadeia incendeiam os céus e uma chuva oblíqua e densa começa a cair.

Salimo, entretanto, indiferente à tempestade que se aproxima, prossegue seu caminho (MOMPLÉ, 2008, p. 78)

No conto que encerra o livro, intitulado "Era outra guerra", são colocadas em confronto duas experiências beligerantes distintas: a Guerra Colonial, que levou Moçambique à independência, e a Guerra dos 16 Anos, conflito interno que se estabeleceu pela tomada do poder na nação. O eixo da narrativa é dado pela percepção de Alberto e Assunção Cereja, um casal de camponeses pobres de Bragança, em Portugal, que foram para Moçambique tentar a vida como pequenos comerciantes.

Como em outros contos do volume, o tempo da narração é o presente, e o espaço é uma nação já apaziguada, tentando se reerguer após décadas de conflitos. Fora de Maputo, entretanto, nas bermas das estradas, ainda são visíveis as cicatrizes destes conflitos:

Os campos espraiam-se em matizes de verde e exalam o fresco odor da terra molhada pela chuva recente. Todavia, os sinais da guerra que há meses terminou

\footnotetext{
${ }^{8}$ Chirove (grafado com $c h$ ) é também o nome de um dos rios de Nampula, uma das províncias com maior população Macua de Moçambique, o que leva a crer que o nome do ritual tenha suas origens na toponímia da região na qual se passa o conto.
} 
estão ainda patentes no capim alto que invadiu as machambas abandonadas, nas palhotas e casas destruídas e também nos carros e machimbombos queimados, macabras sentinelas ao longo da estrada (MOMPLÉ, 2008, p. 81).

A lembrança da Guerra dos 16 Anos, acionada pelas carcaças dos automóveis queimados ao longo da estrada, conflito que fez com que o casal tivesse de permanecer vários anos sitiados em Maputo, os leva ainda mais longe: aos tempos coloniais, quando a Guerra Colonial estava desenrolando-se. Nesta ocasião, os próprios guerrilheiros da FRELIMO, momento antes de tomar a região na qual o casal Alberto e Assunção Cereja tinham seu estabelecimento comercial, orientam o casal a abandonar a região, pois teriam problemas em explicar às autoridades coloniais portuguesas sua opção em permanecer em uma região sob o domínio da FRELIMO. Ao final do conto, o casal rememora as palavras dos guerrilheiros:

\footnotetext{
- Nós sabemos como se torna difícil para vocês sair daqui. Mas é para vos proteger que estamos a pedir que vão embora. Podem levar tudo o que voz pertence: dinheiro, produtos, mobília, tudo. Até podemos apoiar, se for preciso. Mas para Vossa segurança devem sair daqui.

Eles, os colonos portugueses, compreenderam as razões dos guerrilheiros que os queriam proteger da própria tropa colonial. E, seguindo os seus conselhos, uma semana mais tarde, chegaram sãos e salvos à Ilha de Moçambique, com todos os seus haveres (MOMPLÉ, 2008, p. 89-90).
}

\title{
Considerações finais: uma glosa pós-colonial
}

Russell Hamilton, ao realizar um apanhado geral sobre a produção literária dos Países Africanos de Língua Oficial Portuguesa (PALOP), ainda de 1999, afirma o seguinte:

\begin{abstract}
As peculiaridades da história das cinco colônias também têm contribuído para a singularidade da expressão literária dos PALOP. Se bem que seja de certo modo uma simplificação, consta que mais ou menos durante as três derradeiras décadas da época colonial era a expressão literária de reivindicação cultural, protesto social e combatividade que vinha preparando a cena nos cinco PALOP para a atual escrita pós-colonial (HAMILTON, 1999, p. 16).
\end{abstract}

Hamilton não menciona, ao longo do seu artigo, nenhuma obra de Lília Momplé. Curioso fato, uma vez que os três livros da escritora já se encontravam publicados àquela altura. Por que essa ausência? Compreender essa ausência é compreender muito do que está atravancado no meio do longo caminho que separa o público leitor brasileiro das literaturas africanas de língua portuguesa e, em especial, da literatura moçambicana: a circulação de livros e a lógica do mercado editorial.

Caberia perguntar quais os motivos que tornam alguns escritores africanos, tais como Mia Couto e José Eduardo Agualusa, tão presentes e reconhecidos pelos leitores brasileiros, enquanto nomes como os de Paulina Chiziane e Lília Momplé, ou mesmo do afamado poeta José Craveirinha, são praticamente desconhecidos, mesmo dos estudantes de Letras 
brasileiros. Parece-me que o grande problema está na acessibilidade aos livros editados nos próprios países africanos. Infelizmente, só chegam ao conhecimento do público mais amplo de leitores brasileiros a literatura lusófona africana já reconhecida e valorizada, em certa medida, pelo público leitor português, através de edições publicadas por editoras portuguesas. Antes de Mia Couto ou José Eduardo Agualusa serem publicados no Brasil pela Nova Fronteira, eles já circulavam com o devido reconhecimento acadêmico de suas obras em função das edições portuguesas, publicadas pela Editorial Caminho e pela editora Dom Quixote (ALÓS, 2012a; 2012b; 2012c). Apenas em julho de 2012 é que Lília Momplé teve o seu primeiro livro publicado em Portugal (o romance Neighbours). Isso demonstra uma faceta perversa do fluxo de bens simbólicos, em um momento no qual tanto se fala de Weltliteratur, de mundialização do fenômeno literário, e mesmo de uma "República Mundial das Letras" (apenas para recuperar o título do livro publicado pela crítica francesa Pascale Casanova).

Existem ainda elementos residuais do colonialismo marcando presença na lógica do mercado editorial, permeando a circulação de obras literárias africanas em língua portuguesa e dificultando a chegada de muitos autores às livrarias do lado de cá do Atlântico. $\mathrm{O}$ acesso ao Outro, quando esse Outro é o corpus de obras das literaturas africanas de língua portuguesa, ainda está subordinado ao reconhecimento da antiga metrópole colonial, para só então chegar às mãos dos leitores brasileiros.

\section{Referências}

ALMEIDA, Sandra R. G. "Prefácio: apresentando Spivak". In: SPIVAK, Gayatri Chakravorty. Pode o subalterno falar? Belo Horizonte: Editora da UFMG, 2010. p. 7-18.

ALÓS, Anselmo Peres. "Memória cultural e imaginário pós-colonial: o lugar de Lília Momplé na literatura moçambicana”. Caligrama (Belo Horizonte/UFMG), v. 16, n. 1, p. 137158, $2011 \mathrm{a}$.

_ _ “A ficcionalização da história moçambicana nos contos de Lília Momplé”. Estudos

Feministas (Florianópolis/UFSC), v. 19, n. 3, p. 1005-1008, 2011 b.

- "O romance de autoria feminina em Moçambique: Balada de amor ao vento, de

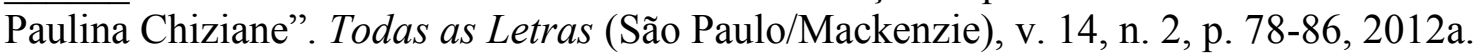

"Literatura comparada ontem e hoje: campo epistemológico de ansiedades e incertezas". Organon (Porto Alegre/UFRGS), v. 27, n. 52, p. 17-42, 2012 b.

. "Identidade nacional em tempos de pós-colonialidade: lendo a moçambicanidade nos romances de Mia Couto". Letras (Santa Maria/UFSM), v. 45, p. 65-82, 2012 c. 
ANÔNIMO. Mia Couto declara-se num vazio após escrever Jesusalém. O País, Maputo,

Edição sem número, p. 3, 24 set. 2009, p. 3.

BHABHA, Homi K. O local da cultura. Belo Horizonte: UFMG, 1998.

CIPIRE, Felizardo. Educação tradicional em Moçambique. 2. ed. Maputo: Publicações Emedil, 1996.

CHIZIANE, Paulina. Balada de amor ao vento. Maputo: Associação dos Escritores Moçambicanos, 1990.

CHIZIANE, Paulina. Balada de amor ao vento. 2. ed. Lisboa: Caminho, 2007.

. "Eu, mulher, por uma nova visão do mundo...”. In. AFONSO, Ana Elisa de Santana

(Org.). Eu, mulher em Moçambique. Moçambique: AEMO; UNESCO, 1992. p. 9-21.

. Ventos do apocalipse. Maputo: Edição da Autora, 1993.

. O sétimo juramento. Lisboa: Caminho, 2000.

. Niketche: uma história de poligamia. Lisboa: Caminho, 2002.

. O alegre canto da perdiz. Lisboa: Caminho, 2008.

COUTO, Mia. O último voo do flamingo. Lisboa: Caminho, 2000.

GRANJO, Paulo. Lobolo em Maputo. Porto: Campo de Letras, 2005.

JUNOD, Henri. Usos e costumes dos bantu. Maputo: Arquivo Histórico de Moçambique, 1996 (Tomo I).

HAMILTON, Russel G. “A literatura dos PALOP e a crítica pós-colonial”. Via atlântica (São Paulo/USP), n. 3, p. 11-22, 1999.

MACHERAY, Pierre. A theory of literary production. Traslated by Geoffrey Wall. London: Routledge, 1978.

MOMPLÉ, Lília. Ninguém matou Suhura. 3. ed. Maputo: Edição da autora, 2007.

Neighbours. 1. ed. Maputo: Associação dos Escritores Moçambicanos, 1995.

. Os olhos da cobra verde. 2. ed. Maputo: Edição da autora, 2008.

RITA-FERREIRA, António. “Os africanos de Lourenço Marques”. Memórias do Instituto de

Investigação Científica de Moçambique. Lourenço Marques: Instituto de Investigação Científica de Moçambique, Série C, 9, 1967-68. p. 95-491.

SCHMIDT, Rita Terezinha. "Em busca da história não contada ou: o que acontece quando o objeto começa a falar?" In: INDURSKY, Freda e CAMPOS, Maria do Carmo (organização). Discurso, memória, identidade. Porto Alegre: Sagra Luzzatto, 2000. p. 102-110. 
SPIVAK, Gayatri Chakravorty. Pode o subalterno falar? Trad. Sandra Almeida, Marcos Feitosa e André Feitosa. Belo Horizonte: Editora da UFMG, 2010.

[Recebido em fevereiro de 2015 e aceito para publicação em agosto de 2015]

\section{The uses of literature: what does Mozambican women write?}

Abstract: Lilia Momplé and Paulina Chiziane rescue the dilemmas of national constitution in their narratives, through the experiences of characters relegated to the sidelines. Despite its importance, the name of these women writers is rarely mentioned in Brazilian studies on African literatures written in Portuguese. Why this absence? Understanding this absence is to understand much of what is cluttered in the middle of the long road that separates the Brazilian readers of African literatures written in Portuguese (particularly the Mozambican literature): the circulation of books and the logic of the publishing market in times marked by residual colonialist cultural politics.

Keywords: Lília Momplé. Paulina Chiziane. Women's writing. Uses of literature. Mozambican narrative. 